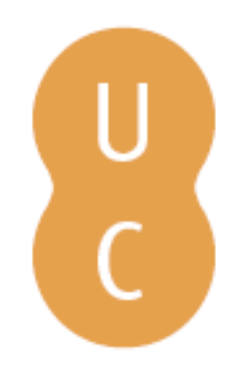

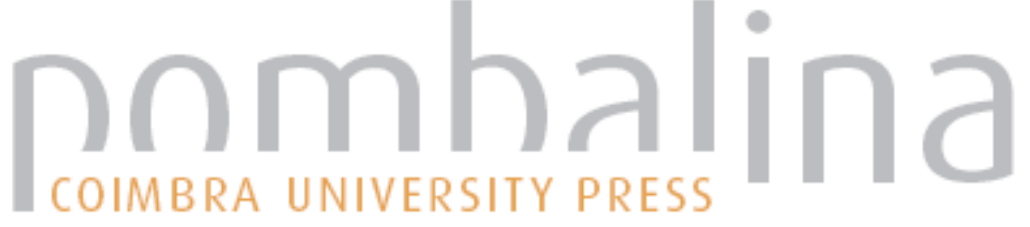

Da liberdade à tolerância: uma leitura pluralista do "On Liberty»

Autor(es): $\quad$ Branco, Tomaz Castello

Publicado por: Imprensa da Universidade de Coimbra

URL

persistente: URI:http://hdl.handle.net/10316.2/31697

DOI: $\quad$ DOI:http://dx.doi.org/10.14195/978-989-26-0204-2_5

Accessed : $\quad$ 26-Apr-2023 10:21:59

A navegação consulta e descarregamento dos títulos inseridos nas Bibliotecas Digitais UC Digitalis, UC Pombalina e UC Impactum, pressupõem a aceitação plena e sem reservas dos Termos e Condições de Uso destas Bibliotecas Digitais, disponíveis em https://digitalis.uc.pt/pt-pt/termos.

Conforme exposto nos referidos Termos e Condições de Uso, o descarregamento de títulos de acesso restrito requer uma licença válida de autorização devendo o utilizador aceder ao(s) documento(s) a partir de um endereço de IP da instituição detentora da supramencionada licença.

Ao utilizador é apenas permitido o descarregamento para uso pessoal, pelo que o emprego do(s) título(s) descarregado(s) para outro fim, designadamente comercial, carece de autorização do respetivo autor ou editor da obra.

Na medida em que todas as obras da UC Digitalis se encontram protegidas pelo Código do Direito de Autor e Direitos Conexos e demais legislação aplicável, toda a cópia, parcial ou total, deste documento, nos casos em que é legalmente admitida, deverá conter ou fazer-se acompanhar por este aviso.

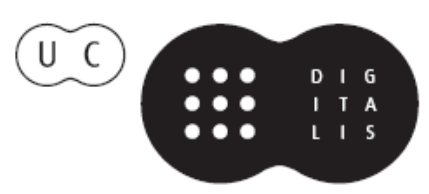


Carlos Camponez

Ana Teresa Peixinho

Coordenação

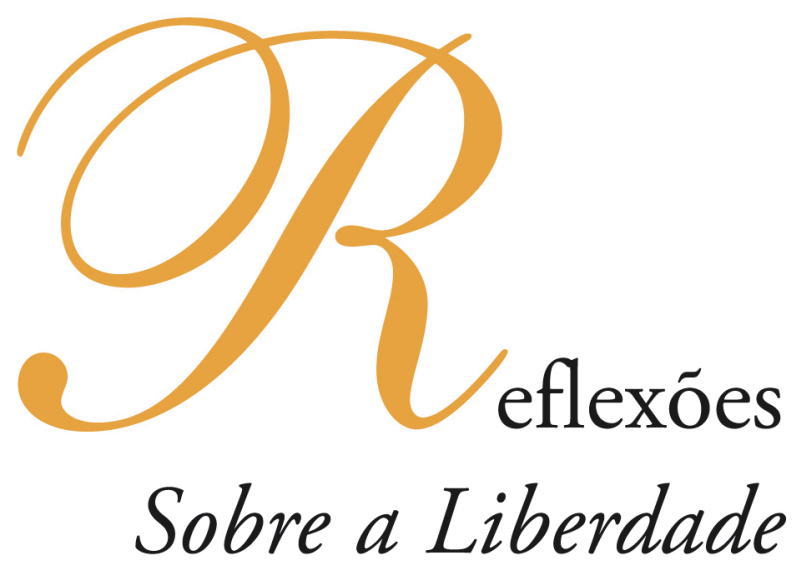

150 anos da obra de John Stuart Mill

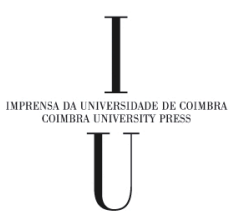




\title{
DA LIBERDADE À TOLERÂNCIA: \\ UMA LEITURA PLURALISTA DO «ON LibERTY»
}

\section{Tomaz Castello Branco}

\begin{abstract}
A parte realmente convincente do argumento de Mill é aquela em que ele mostra
quão frequentemente a intolerância esteve do lado da falsidade.

O cepticismo, ou a dúvida, é o parente legítimo da tolerância.
\end{abstract}

Frederic William Maitland, Liberty and Equality (1875)

O ensaio "Sobre a Liberdade», de John Stuart Mill, é frequentemente apontado como uma das mais vigorosas apologias da liberdade individual alguma vez escritas. Não obstante, gostaríamos de sugerir que este ensaio também comporta, em paralelo, uma segunda apologia. $\mathrm{Na}$ verdade, ele pode, e deve, ser lido sob o prisma de um outro valor: o da tolerância.

Lido o ensaio sob este enfoque, podemos dele extrair duas grandes linhas de argumento que confluem na sustentação deste valor eminentemente político. Designamos estas duas linhas como o argumento da liberdade e o argumento do conhecimento. A primeira decorre directamente, claro está, do próprio princípio da liberdade, também conhecido como princípio do dano.

O objecto deste ensaio é o de estatuir um princípio muito simples, com o intuito de governar absolutamente as relaçóes entre a sociedade e o indivíduo sob a forma de compulsão e controlo, quer os meios utilizados sejam a força física sob a forma de penalidades legais, ou a coerção moral da opinião pública. Esse princípio é o de que o único fim para o qual a espécie humana está mandatada, individual ou colectivamente, para interferir com a liberdade de acção de algum de entre os seus, é o da auto-protecção. Que o único propósito para o qual o poder pode ser legitimamente exercido sobre qualquer membro de uma comunidade civilizada, contra a sua vontade, é o de prevenir o dano a terceiros. O seu próprio bem, físico ou moral, não é mandato suficiente.

«(...) A única parte da conduta de quem quer que seja, pela qual se é responsável perante a sociedade, é aquela que diz respeito a terceiros. Na parte que apenas diz respeito a si próprio, a sua independência é, por direito, absoluta. Sobre si próprio, sobre o seu próprio corpo e mente, o indivíduo é soberano» (Mill, 1962: 135).

Do ponto de vista do exercício do poder - e, não se deve nunca perder de vista que a aplicação do princípio de Mill não se restringe ao poder político organizado e institucionalizado no aparelho de Estado, mas a toda e qualquer forma de poder que possa exercer a sua influência sobre o indivíduo contra a vontade deste - e também, seguramente, por força da sua própria formulação negativa, o que aqui está verdadeiramente em causa é a estatuiçáo de um princípio de tolerância, cuja extensão se considera inversamente proporcional aos danos que possa causar. Esta interpretação encontra eco em Mary Warnock quando, referindo-se ao «harm principle», afirma que:

"O argumento de Mill é o de que o único limite à tolerância, a única razão válida para não tolerar um tipo de comportamento, é que este comportamento cause dano a outras pessoas que não aquelas que o praticam» (Warnock, 1987: 123. 
No mesmo sentido pronuncia-se Glyn Morgan:

«Independentemente das palavras para o expressar, o propósito [do harm principle] permanece o de identificar precisamente onde se traçam as fronteiras entre a liberdade protegida e a coerçâo legítima, porque estas fronteiras marcam os limites da tolerância» (Morgan, 2008: 147).

Aliás, é esta conexão estreita entre a liberdade e a tolerância que também Isaiah Berlin estabelece quando, antes de apresentar a definição do conceito de liberdade negativa, procura situá-la na resposta a uma pergunta específica:

"Qual é a área na qual o sujeito - uma pessoa ou grupo de pessoas - é, ou deve ser deixada em paz para fazer, ou ser, aquilo que ela é capaz de fazer, ou ser, sem a interferência de outras pessoas?» (Berlin, 1969: 121-2).

A tolerância surge, assim, como reflexo, ou melhor, como o verdadeiro pano de fundo da liberdade individual concebida de forma negativa. Ou, dito de outra forma, a conceptualização negativa da liberdade não é mais do que a adequação da reflexão da liberdade ao princípio da tolerância. Será essa, afinal, nas palavras de Mill, «a única liberdade merecedora do nome» (Mill, 1962: 138).

\section{O argumento do conhecimento como justificaçáo da Liberdade}

No segundo Capítulo do On Liberty, Stuart Mill avança uma segunda linha de argumento que surge como principal justificação de um elemento fundamental da liberdade individual: a liberdade de expressão. Esta linha, que designámos como argumento do conhecimento, parte da sua crença na humanidade como espécie essencialmente autocriativa, num crescimento perpétuo resultante das chamadas "experiências em vivência» (experiments in living); parte, no fundo, da sua visão das pessoas como «seres em progresso». Mill acredita na liberdade como condição básica para que a espécie humana, como um todo, avance e progrida. Neste sentido, uma das principais justificaçôes, senão a principal, em que assenta o princípio do dano é a da garantia de um espaço de tolerância, táo alargado quanto possível. Esse espaço, na linha do que designámos como o argumento do conhecimento, tem como consequência a máxima abertura à liberdade de expressão. Para a visão progressista de Mill, a Liberdade é o verdadeiro motor do progresso humano. ${ }^{42}$

«O maior mal é o que é feito àqueles que não são heréticos, e cujo completo desenvolvimento mental é prejudicado, e a sua razão tolhida, pelo medo da heresia. Quem pode calcular o que o mundo perde na multidáo de intelectos promissores combinados com caracteres tí-

42 Esta é uma ideia que, no quadro da teoria política mais contemporânea, é indissociável do pensamento de Hayek. A sua defesa da Liberdade como o mais revolucionário desencadeador do progresso humano é marcante em toda a sua obra e verdadeiramente emblemática do arranque do seu argumento em The Road to Serfdom. Neste sentido, o liberalismo aparece como o culminar ou, pelo menos, o estádio mais avançado, de uma longuíssima senda de progresso tornada possível pela afirmação da Liberdade. Os dois grandes planos operativos da Liberdade seriam o comércio e a ciência. São eles os motores do progresso humano; motores movidos a Liberdade. A lógica hayekiana é simples: quanto maior for a liberdade, maior será a aceleração do progresso (V. Hayek, 1991: 10-12). 
midos, que não ousam perseguir nenhuma linha de pensamento arrojada, vigorosa e independente» (Mill, 1962: 160).

A tolerância é, assim, uma condição para a Liberdade e esta, na medida em que é fundamental para o desenvolvimento do conhecimento, para o progresso. Como Glyn Morgan bem aponta, «Mill estava absolutamente correcto quando apontava que o estado do conhecimento é a determinante principal da mudança social» (Morgan, 2008: 162). Para Stuart Mill, inglês oitocentista, no auge do poder imperial britânico, a principal virtude da sua sociedade - herdeira da primeira grande revoluçáo industrial, eixo do comércio internacional, mas também refúgio para os mais diversos dissidentes intelectuais que nela encontravam a paz e a segurança (e a tolerância?) necessárias para o desenvolvimento das suas propostas, tantas vezes revolucionárias -, aquela que lhe garantia o seu poder, quase hegemónico, residia, fundamentalmente, na sua capacidade de manter vivo um processo de conhecimento cujo desenvolvimento intensivo liderava nos mais diversos campos do saber.

Mill vê o processo e desenvolvimento do conhecimento como uma «busca interminável» ${ }^{43}$ pela verdade. Uma busca que nunca estará terminada, ou melhor, cujo término nunca poderemos definir, precisamente por causa da natureza incompleta e falível do conhecimento humano. Ora, é precisamente esta concepção falibilista do conhecimento humano que está na base da sua reflexão e justificação do valor da tolerância. Assim entendido, o falibilismo de Mill pode ser visto sob duas perspectivas fundamentais e interdependentes: uma primeira, que, assentando na ideia da incompletude do permanente processo do conhecimento, convida à diversidade, isto é, que procura manter em aberto o espaço de discussão e de confronto de pontos de vista acerca da verdade; numa segunda perspectiva, o falibilismo milliano impede que qualquer dos pontos de vista em conflito possa arrogar-se da pretensão de pôr um fim ao processo do conhecimento.

De acordo com Mill, o próprio erro é útil ao processo de conhecimento. Por mais evidente que seja, a sua expressão, tornando-o evidente, contribuirá para clarificar e fortalecer a verdade. Por essa mesma razão, a expressão do erro deve ser politicamente protegida conquanto, claro está, não seja causadora de danos a terceiros.

«A verdade ganha mais mesmo com os erros daquele que, com o devido estudo e preparação, pensa por si próprio, que pelas opiniốes verdadeiras daqueles que só as sustentam porque, eles próprios, não são capazes de pensar» (Mill, 1962: 160).

Assim, qualquer tentativa de purificação do processo de conhecimento, nomeadamente através do silenciamento de opinióes que consideramos serem erradas, é indesejável, porque prejudicial para o próprio processo de conhecimento. A opiniáo silenciada poderá ser errada, mas o seu silenciamento é um erro ainda maior. E, se a manifestaçáo de uma opiniāo errada é merecedora de tolerância, a tentativa do seu silenciamento não o será.

A propósito, diz Mill:

«(...) embora a opinião silenciada seja errada, ela pode conter, e muito frequentemente contém, uma porção da verdade; e, uma vez que a opiniáo geral ou prevalente sobre qualquer assunto raramente, ou nunca, contém a verdade na sua totalidade, só pela colisão de opiniôes

43 A expressão é de Karl Popper (V. Popper, 2002). 
adversas poderá ter o remanescente da verdade alguma hipótese de alguma vez ser alcançado» (Mill, 1962: 180).

Para Mill, não há qualquer dúvida que o «mal formidável», o pior dos males, "não é o conflito violento entre partes da verdade, mas a silenciosa supressão de uma das suas metades» (Mill, 1962: 180). Neste sentido, a prática da tolerância, traduzida na liberdade de expressão, é, não apenas consentânea, mas essencial ao próprio processo de busca da verdade - processo esse que é elementar à própria concepção da espécie humana como espécie em progresso permanente (progressive beings).

\section{O erro e a verdade como reconciliaçáo e combinação de opostos}

Mas, se o erro deve continuar a ser admitido ao confronto permanente de opinióes, também a verdade, mesmo admitindo a hipótese de a termos alcançado em definitivo, na sua totalidade, nem por isso deve ser isenta do escrutínio permanente a que as opinióes devem ser sujeitas:

«(...) mesmo se uma determinada opinião for, não apenas verdade, mas toda a verdade, a menos que possa ser sujeita à contestação honesta e vigorosa, e o for efectivamente, ela será tomada, pela maioria daqueles que a aceitarem, como se tratasse de um preconceito, com pouco sentido ou compreensão dos seus fundamentos racionais» (Mill, 1962: 180-1).

No limite, a própria expressão, intolerante, daquele que se arroga detentor de toda a verdade, deve, também ela, ser tolerada. Esse será «o preço a pagar por um bem inestimável». É certo que uma tal arrogância, «a pretensão exclusiva feita por uma parte da verdade como sendo a sua totalidade, deve e tem que ser contestada». Mas isso não significa que mesmo ela possa ser suprimida: «ela pode ser lamentada, mas tem que ser tolerada» (Mill, 1962: 179).

«A não ser que as opinióes favoráveis à democracia e à aristocracia, à propriedade e à igualdade, à cooperaçáo e à competição, ao luxo e à abstinência, à socialidade e à individualidade, à liberdade e à disciplina, e a todos os outros antagonismos presentes na vida prática, sejam expressos com igual liberdade, e promovidos e defendidos com igual talento e energia, não há qualquer hipótese de ambos os elementos obterem o que lhes é de direito: uma escala certamente subirá e a outra descerá. A verdade, nos grandes assuntos práticos da vida, é (...) uma questão de reconciliação e combinação de opostos» (Mill, 1962: 175).

Esta é uma conclusão que Mill repete com frequência. Esta é uma conclusão que aponta abertamente para uma configuraçáo pluralista do conhecimento dos valores, na medida em que admite e assinala, não apenas o conflito entre o verdadeiro e o errado, mas o conflito no seio da própria verdade. Nas palavras do próprio Mill:

«Considerámos duas hipóteses: que a opinião recebida possa ser falsa, e uma qualquer outra opinião, consequentemente, verdadeira; ou que, sendo a opinião recebida verdadeira, um conflito com o erro que se lhe opõe seja essencial para uma clara apreensão e um sentimento profundo da sua verdade. Mas há um caso mais comum que estes; quando as doutrinas conflituantes, ao invés, de serem uma verdadeira e a outra falsa partilham a verdade entre elas» (Mill, 1962: 173). 
E aqui Mill revela um apurado «sentido da realidade» no que diz respeito à reflexão epistemológica sobre o humano e sobre o político. Contrariamente a áreas do conhecimento, como a matemática, "onde não há nada a dizer acerca do lado errado da questáo", onde "todo o argumento repousa sobre um dos lados», no domínio da ética encontramos frequentemente disputas onde pudemos facilmente observar precisamente o contrário:

«em qualquer assunto no qual a diferença de opinióes seja possível, a verdade depende de um equilíbrio a ser alcançado entre dois conjuntos de razóes conflituantes» (Mill, 1962: 163).

É este, afinal, o cenário que encontramos «quando nos viramos para assuntos infinitamente mais complicados, para a moral, para a religião, para a política, para as relaçóes sociais, e para os afazeres da vida» (Mill, 1962: 163). Este é um cenário que nos aponta para o pluralismo; um pluralismo que decorre não apenas da observaçáo do político, mas que se justifica pelo próprio interesse da verdade: «o interesse da verdade requer uma diversidade de opiniốes» (Mill, 1962: 179). Pois que, de acordo com Mill, «só através da diversidade de opinióes pode existir, no estado actual do intelecto humano, uma hipótese de fair-play para todos os lados da verdade» (Mill, 1962: 175-6). O pluralismo é, assim, um requisito elementar ao próprio processo do conhecimento e, por esta mesma razáo, torna-se um requisito elementar na busca da verdade.

Por outro lado, Mill não só não vê o conflito como uma ameaça à verdade, como nem sequer acredita, ingenuamente, que do conflito emergirá sempre a verdade. Em bom rigor, nada nesta lógica impede que o conflito não termine com o triunfo do erro. O que Mill sugere é que, se por um lado, o conflito de posições contrárias é endémico ao próprio processo de conhecimento, por outro, e em virtude da sua crença no progresso, Mill acredita que, ainda que determinado conflito resulte num desvio face à verdade, a prazo, e porque esse resultado será ele próprio permanentemente sujeito à confrontação com novas posiçôes, a aproximação à verdade, mesmo que temporariamente atrasada, retomará o seu curso ${ }^{44}$. Esta é, aliás, «a grande vantagem da verdade»:

«A grande vantagem da verdade consiste nisto, que quando uma opiniáo é verdadeira, ela pode ser extinta uma, duas ou muitas vezes mas, no decurso dos tempos, encontramos geralmente pessoas capazes de a redescobrir (...)» (Mill, 1962: 155).

Por isso mesmo é que, como já referimos, uma regra que esta reflexão não pode deixar de extrair é a de que as posiçóes adoptadas devem ser provisórias, precisamente por causa da natureza provisória do entendimento da verdade no decurso do processo de conhecimento. Ora, tal como no domínio epistemológico, a provisoriedade implica que determinada

$44 \mathrm{Ou}$, como o próprio Mill afirma: «À medida que a espécie humana melhora (improve), o número de doutrinas que não são mais disputadas ou postas em dúvida, crescerá constantemente: e o bem-estar da espécie humana quase poderá ser medido pelo número e gravidade das verdades que alcançaram o estatuto de se tornarem incontestadas» (Mill, 1962: 171). Porém, a "consolidaçấo da opinião» que este movimento envolve, embora possa ser «salutar» no caso das opiniōes verdadeiras, será "perigoso» no caso das opinióes erradas. E, precisamente, o problema está em que, como nunca nos podemos situar fora do processo de conhecimento, nunca poderemos afirmar, com certeza, se a consolidação da opinião é salutar ou perigosa. Não obstante, acreditamos que, de acordo com os princípios enunciados por Mill, a sua posição tenderia a inclinar-se para, por defeito, considerar uma tal consolidação como perigosa, o que o levará a nunca abandonar o entendimento do carácter provisório da verdade. 
posição que é tomada como verdadeira possa ser revista, também no domínio do político se entende, decorrentemente, que a adopção de quaisquer políticas não deverá deixar de contemplar a possibilidade de revisão. As políticas, tal como as etapas do processo de conhecimento, deverão então ser consideradas de forma provisória e reversível ${ }^{45}$. Esta regra decorre da ideia do permanente progresso do conhecimento humano, que assenta na capacidade de identificar o erro e assim, de forma tentativa e provisional, corrigir a posição anterior, num movimento perpétuo de aproximação à verdade. A incorporação do erro como característico e elementar do processo político é assim encarada de uma forma tão natural como aquela em que ele é concebido no processo do conhecimento. Como Mill diria, "uma qualidade da mente humana, a fonte de tudo o que é respeitável no homem, quer como ser intelectual, quer como ser moral, é que os seus erros são corrigíveis» (Mill, 1962: 146). Esta será uma característica inerente ao processo do conhecimento humano e, como tal, extensível aos produtos da razão humana, incluindo a política.

É neste sentido que a reflexão de Mill sobre a liberdade de expressão aconselha a uma verdadeira política de tolerância fundada na mais extensa possível exposição de argumentos e na mais profunda discussão dos mesmos. Isto é, uma prática de tolerância alicerçada num racionalismo crítico, porque anti-dogmático, na permanente discussão de pontos de vista, no constante confronto de opinióes acerca da verdade, que terá como consequência o aprofundamento do conhecimento e o decorrente progresso da humanidade. Uma política que convida, muito no espírito da fantasia de Vico, da Einfuhlung de Herder, ou mesmo da sympathy de Adam Smith, a que "cada um mergulhe na posição mental daqueles que dele diferem» (Mill, 1962: 163). Quem o fizer, não apenas conhecerá melhor a posição do outro, mas também a sua própria posição. Pois que,

«aquele que conhece apenas a sua versão do assunto, conhece-o pouco. As suas razôes poderão ser boas, e pode ninguém ter sido capaz de as refutar. Mas se ele for igualmente incapaz de refutar as posiçóes da posição contrária; se ele nem sequer souber em que consistem, ele não tem qualquer fundamento para preferir qualquer posição de entre ambas. A posição racional para ele seria uma suspensão do julgamento e, a não ser que ele se contente com isso, ele será levado, ou pela autoridade, ou adoptará, como a generalidade do mundo, a posição em relação à qual sinta maior inclinação» (Mill, 1962: 163).

45 É notável como a epistemologia de Stuart Mill prenuncia, em larga medida, o falibilismo que Karl Popper viria a desenvolver na sua Lógica da Descoberta Cientifica. Muito sinteticamente, este pode ser traduzido como a tese segundo a qual o conhecimento humano é falível porque essencialmente conjectural, pelo que, ironicamente, a aproximação à verdade é feita através de um processo contínuo de identificação, definição e afirmação dos erros. Neste sentido a verdade, cuja natureza náo poderá deixar de ser uma inter-subjectividade, terá sempre um estatuto provisório que decorre da sua sujeição permanente à possibilidade de refutação. Como Karl Popper sustentaria, a recusa de sujeitar o que quer que tomemos como verdade «à contestação honesta e vigorosa" não é mais que uma evidência de arrogância intelectual - essa sim, porque impeditiva do progresso e prejudicial à busca contínua da verdade, seria, aos olhos de Popper, intolerável. Como o próprio explicaria em The Poverty of Historicism:

«Este método pode ser usado, mais precisamente, com vista a buscarmos, e a combatermos contra, os maiores e mais urgentes males da sociedade, ao invés de procurarmos, e lutarmos por, algum bem último (como os holistas tendem a fazer). Mas, uma luta sistemática contra males definitivos, contra formas concretas de injustiça e de exploração, e sofrimentos evitáveis, como a pobreza ou o desemprego, é uma coisa muito diferente da tentativa de realizar um ideal e distante plano (blueprint) da sociedade» (Popper, 1974: 91). 
Isto é, para Mill, no plano epistemológico, o contrário do racionalismo crítico será a cedência ao irracionalismo (ou, pelo menos, a uma certa forma de emotivismo, entendido aqui como a submissão ao domínio das paixôes) ou à adopção de uma posição de racionalismo dogmático. No plano político, a alternativa à prática da tolerância, no respeito pela liberdade de expressão, levará ao relativismo e à arbitrariedade moral, ou ao autoritarismo e à anulação da Liberdade. É por isso mesmo que, tal como a «verdade depende de um equilíbrio», também a política dele depende.

\section{A Tolerância como condição do progresso humano}

O liberalismo de Mill traduz, afinal, uma profunda reacção individualista contra a interferência de terceiros na busca de cada um pela sua própria concepção do bem e da vida boa. É este o sentido em que se torna clara a defesa dos famosos «experiments in living». Estes dependem efectivamente da diversidade que resulta da natureza complexa que é atributo da humanidade mas são também, simultaneamente, a garantia da sobrevivência dessa mesma humanidade. É por isso que:

«A única liberdade merecedora do nome é a de prosseguirmos o nosso próprio bem à nossa própria maneira, conquanto não tentemos privar os outros das deles, ou impedir os seus esforços para as alcançarem» (Mill, 1962: 138).

Não surpreendentemente, assim considerada, a Liberdade não é mais que um sinónimo de tolerância. O que preocupa Mill é a garantia da possibilidade de cada um poder trilhar o seu próprio caminho, possibilidade essa que deve sempre ser equilibrada com a impossibilidade de obstruir os caminhos dos outros ${ }^{46}$. O que náo o preocupa é que todos os caminhos

46 É esta garantia que Glyn Morgan traduz como a segurança indispensável para «prosseguirmos o nosso próprio bem à nossa própria maneira», que estará verdadeiramente na base da justificação da liberdade em Stuart Mill, e que serve de guia para o enquadramento de uma política de tolerância. A prossecuçáo do nosso próprio bem à nossa própria maneira pressupóe que cada um disporá da segurança necessária para trilhar o seu próprio caminho. Porém, o texto do On Liberty não explora suficientemente esta questão da segurança, como, aliás, Glynn Morgan bem adverte. Será, portanto, necessário recorrer a outros textos de Stuart Mill, nomeadamente o Utilitarianism, para melhor compreendermos o seu significado. Aí poderemos, segundo Morgan, encontrar a afirmação clara da segurança como «o mais vital de todos os interesses»; aquele «do qual nenhum ser humano pode prescindir; e do qual toda a nossa imunidade face ao mal depende». A segurança será o elemento que nos permite perspectivar «o nosso próprio bem» no tempo, de forma continuada, conferindo sentido à própria noçáo de «seres em progresso». Sem ela, não poderíamos almejar a mais que a uma pobre "gratificação instantânea». Como Glyn Morgan bem sustenta: «A segurança também figura proeminentemente na noção de Mill de progresso e no seu entendimento de civilização. (...) a segurança envolve não meramente a segurança física imediata, de curto prazo, mas uma protecção durável, de longo prazo, da personalidade e da propriedade. $\mathrm{Na}$ ausência desta protecção, os indivíduos teriam apenas acesso momentâneo aos seus bens, eles nunca alcançariam a tranquilidade psicológica. Mais ainda, em sociedades inseguras os indivíduos seriam incapazes de poupar e planear o futuro. Mill vê a segurança (entendida desta forma extensiva) tanto como uma pré-condição como característica definitiva de uma sociedade civilizada».

Assim, continua o professor de Harvard: «O argumento de Mill sobre a liberdade repousa sobre a ideia segundo a qual o nosso interesse vital na segurança requer a emergência de um carácter progressivo, não meramente nuns poucos indivíduos, mas a uma escala societal». Essa é, afinal, a razão do sucesso das «sociedades liberais modernas»: "proteger todos os cidadãos em termos minimamente iguais contra as principais e evitáveis inseguranças da vida». Por isso mesmo, conclui Glyn Morgan: «só os interesses da segurança podem justificar a coerção.» (Morgan, 2008: 150, 151, 159, 162, 163; As citaçóes de Mill são referentes a Mill, 1963-1991: 250-1). 
trilhados sejam, por necessidade, os caminhos correctos ou verdadeiros. O que o preocupa, em suma, é a existência de uma pluralidade de caminhos.

Mas, note-se bem, o desejo de Mill de «proteger os dissidentes e os heréticos enquanto tal» não resulta meramente de uma concepção da liberdade individual sustentada por um princípio de reciprocidade simples. Em boa verdade, o seu alcance é muito maior. A protecção da liberdade individual não é estabelecida meramente em nome do interesse individual, mas do interesse comum. A preservação da «variedade é do interesse comum pois que é dela que depende o próprio processo e progresso do conhecimento humano. É esta a tese central de toda a segunda secção do On Liberty. Assim perspectivada, a liberdade não é uma consequência da escolha verdadeira; pelo contrário: a verdade é que poderá ser produto do exercício livre de escolhas. Em bom rigor, afastando a própria possibilidade do estabelecimento definitivo e unitário da verdade - ambição que considera sempre antitética com a garantia da liberdade individual -, Mill considera antes a liberdade como condição necessária ao próprio processo do conhecimento. Segundo Berlin:

«No centro do pensamento e do sentimento de Mill encontra-se, não o seu utilitarismo, nem a preocupação com o esclarecimento (enlightenment), nem com a separação do domínio privado do do público (...), mas a sua crença apaixonada de que os homens são tornados humanos pela sua capacidade para a escolha - escolha do bem e do mal igualmente. A falibilidade, o direito ao erro, como corolário da capacidade para o auto-melhoramento; a desconfiança da simetria e da finalidade como inimigas da liberdade - estes são os princípios que Mill nunca abandona. Ele permanece agudamente ciente do carácter multifacetado da verdade e da irredutível complexidade da vida, que descarta a própria possibilidade de qualquer solução simples, ou a ideia de uma resposta final para qualquer problema concreto» (Berlin, 1969: 192).

De acordo com o enfoque pluralista que Isaiah Berlin faz sobre o «pequeno grande livro» de Mill - na feliz expressão de Sir Richard Livingstone - a tolerância que devemos à expressão livre de cada indivíduo excede a lógica em que se funda o conceito de liberdade negativa em sentido estrito. Isto é, a esfera de liberdade individual deve ser assegurada não apenas por respeito ao interesse individual de cada um - ideia que está na base do chamado «harm principle» -, mas por respeito ao interesse geral da própria humanidade. Nas palavras de Mill:

Mas o mal peculiar do silenciamento da expressão de uma opinião é de se está a roubar a espécie humana; tanto a posteridade como a presente geração; aqueles que discordam da opiniẫo ainda mais que aqueles que a sustêm. Se a opiniấo estiver correcta, eles ficam privados da oportunidade de trocarem o erro pela verdade; se estiver errada, eles perdem, o que é quase um tão grande benefício, a percepção clara e a vivificante impressão da verdade, produzida pela sua colisão com o erro" (Mill, 1962: 142).

Assim, negando a possibilidade de nos afirmarmos na posse da verdade absoluta e, portanto, final, o que Mill afirma é que o nosso conhecimento é sempre imperfeito, incompleto, falível - ou, pelo menos, que, ainda que tenhamos realmente alcançado a verdade derradeira sobre qualquer assunto, nunca estaremos em condiçóes de o podermos assegurar com certeza, pondo assim um termo definitivo ao debate sobre esse mesmo assunto. E, como tal, qualquer expressão de opinião pode, em princípio, contribuir para o avanço do conhecimento humano - constituindo-se, como tal, em benefício geral. Assim, diz Mill: 
«Todo o silenciamento da discussão é uma assumpção de infalibilidade» (Mill, 1962: 143). Ora, a assumpção da falibilidade do conhecimento humano implica, obviamente, a afirmaçáo do carácter provisório da verdade. E esta convida ao concurso, quanto mais aberto possível, do maior número de contributos possíveis. Neste sentido, questiona Berlin: «Sem a infalibilidade como pode a verdade emergir senão através da discussão?» (Berlin, 1969: 186) O dever de tolerarmos aquilo que nos parece errado, ou meramente inútil, decorre, portanto, desta assumpção da falibilidade do conhecimento; e, o que é mais, do desejo de nos aproximarmos da verdade e de nos afastarmos do erro. Reforçando esta ideia acerca da natureza provisória do conhecimento, Mill afirma que:

«Existe a maior diferença entre presumir uma opiniáo como sendo verdadeira, porque com todas as oportunidades para a contestar, ela não foi refutada, e assumir a sua verdade com o propósito de não se permitir a sua refutação» (Mill, 1962: 145).

Podemos encontrar aqui um contraste essencial entre as ideias de tolerância e de intolerância. A primeira celebra o conhecimento como uma demanda permanente, como uma busca permanentemente inacabada da verdade, nunca tomada como definitiva mas sempre tentativa ou provisória, na qual a liberdade (de pensamento e de expressão) desempenha o papel fundamental de colocar este processo sobre o questionamento permanente. É neste sentido que melhor se compreende o papel essencial da tolerância, na medida em que, em prol desta demanda, todas as contribuiçôes - quantas mais, melhor - devem ser admitidas a concurso. Se reconhecermos que não sabemos de antemão o destino de todo este processo, então, teremos que admitir que o seu sucesso dependerá do maior número de avenidas que pudermos trilhar - mesmo o caminho que se revele infrutífero não deixará, também ele, de ter o seu préstimo, tal como num percurso rodoviário um sinal de beco sem saída tem o mérito de poupar ao condutor o incómodo de percorrer a totalidade do troço assinalado para só no final se aperceber que terá de regressar ao ponto de partida.

Pelo contrário, a segunda ideia, correspondente à de intolerância, tende a traduzir-se num fechamento da verdade. Pois que, «a menos que seja contraditada, a verdade arrisca-se a degenerar em dogma ou preconceito». (Berlin, 1969: 189) Não permitindo a sua refutação, o intolerante, embora talvez pretendendo fortalecer aquilo que toma como verdade, acaba por a enfraquecer, já que, não permitindo a liberdade de expressóes contrárias à sua, não permite sequer o robustecimento contínuo que eventualmente poderia decorrer caso conseguisse responder com sucesso às críticas que contra ela seriam desferidas. Mas, o mal maior é que, ao fazê-lo, o intolerante está a «roubar a espécie humana» (Mill, 1962: 189). Rouba-lhe a possibilidade de contribuir para o processo contínuo em que se desenrola o conhecimento humano.

Mill entende a autonomia individual, a capacidade de cada um se responsabilizar por si próprio, como degrau inicial para um estatuto de humanidade plena; e vê a espécie humana como sendo constituída por «seres em progresso», como uma espécie singularizada pelo seu poder criativo e caracterizada por um progresso permanente que é mantido sempre em aberto por uma busca interminável do conhecimento - conhecimento esse que é entendido como nunca encerrado e é orientado por uma busca da verdade que nunca poderá ser encerrável.

É nestes termos que, por um lado, Mill acredita no valor da liberdade individual e defende-o procurando limitar ao máximo a legitimidade da interferência externa na esfera 
do indivíduo. É também nestes termos que, por outro lado, Mill acredita que a condição básica para que a espécie humana, como um todo, progrida, é a da manutenção de um espaço de tolerância, tão alargado quanto possível, que encoraje o concurso do máximo de contribuiçóes possíveis com vista a esse propósito.

\section{Bibliografia:}

BERLIN, Isaiah, (1969), Four Essays on Liberty, Oxford, Oxford University Press.

HAYEK, Friederich A. von, (1991), The Road to Serfdom, London, Routledge, 1944, 1991.

MILL, John Stuart, (1962), On Liberty, in: Mary Warnock (Ed.), John Stuart Mill, Utilitarianism, London, Fontana Press.

MILL, John Stuart, (1963-1991), Utilitarianism in Collected Works of John Stuart Mill, John M. Robson (Ed.), Toronto, Toronto University Press.

MORGAN, Glyn, (2008), «The Mode and Limits of John Stuart Mill's Toleration» in: Melissa S. Williams and Jeremy Waldron, Toleration and Its Limits, New York and London, New York University Press, 139-167.

POPPER, Karl R., (1974), The Poverty of Historicism, London, Routledge \& Kegan Paul, 1957, 1974.

POPPER, Karl R., (2002), Unended Quest: An Intellectual Biography, London, Routledge, 1976, 2002.

WARNOCK, Mary, (2001), «The Limits of Toleration» in: Susan Mendus, David Edwards (Ed.s), On Toleration, Oxford, Oxford University Press. 